\title{
BMJ Open Cost-effectiveness of unicompartmental compared with total knee replacement: a population-based study using data from the National Joint Registry for England and Wales
}

\author{
Edward Burn, ${ }^{1}$ Alexander D Liddle, ${ }^{1,2}$ Thomas W Hamilton, ${ }^{1}$ Andrew Judge, ${ }^{1,3,4}$ \\ Hemant G Pandit, ${ }^{1,5}$ David W Murray, ${ }^{1,5}$ Rafael Pinedo-Villanueva ${ }^{1,3}$
}

To cite: Burn E, Liddle AD, Hamilton TW, et al. Cost-effectiveness of unicompartmental compared with total knee replacement: a population-based study using data from the National Joint Registry for England and Wales. BMJ Open 2018;8:e020977. doi:10.1136/ bmjopen-2017-020977

- Prepublication history and additional material for this paper are available online. To view these files, please visit the journal online(http://dx.doi. org/10.1136/bmjopen-2017020977).

Received 4 December 2017 Revised 6 March 2018 Accepted 15 March 2018
Check for updates

For numbered affiliations see end of article.

Correspondence to Dr David W Murray; david.murray@ndorms.ox.ac.uk

\section{ABSTRACT}

Objectives To assess the value for money of unicompartmental knee replacement (UKR) compared with total knee replacement (TKR).

Design A lifetime Markov model provided the framework for the analysis.

Setting Data from the National Joint Registry (NJR) for England and Wales primarily informed the analysis. Participants Propensity score matched patients in the NJR who received either a UKR or TKR.

Interventions UKR is a less invasive alternative to TKR, where only the compartment affected by osteoarthritis is replaced.

Primary outcome measures Incremental qualityadjusted life years (QALYS) and healthcare system costs. Results The provision of UKR is expected to lead to a gain in QALYs compared with TKR for all age and gender subgroups (male: $<60$ years: $0.12,60-75$ years: 0.20 , $75+$ years: 0.19 ; female: $<60$ years: $0.10,60-75$ years: $0.28,75+$ years: 0.44 ) and a reduction in costs (male: $<60$ : $£-1223,60-75$ years: $£-1355,75+$ years: $£-2005$; female: $<60$ years: $£-601,60-75$ years: $£-935,75+$ years: $£-1102$ per patient over the lifetime). UKR is expected to lead to a reduction in QALYS compared with TKR when performed by surgeons with low UKR utilisation but an increase among those with high utilisation $(<10 \%$, median 6\%: $-0.04, \geq 10 \%$, median $27 \%$ : 0.26). Regardless of surgeon usage, costs associated with UKR are expected to be lower than those of TKR ( $<10 \%$ : $£-127, \geq 10 \%$ : $£-758)$.

Conclusions UKR can be expected to generate better health outcomes and lower lifetime costs than TKR. Surgeon usage of UKR does, however, have a significant impact on the cost-effectiveness of the procedure. To achieve the best results, surgeons need to perform a sufficient proportion of knee replacements as UKR. Low usage surgeons may therefore need to broaden their indications for UKR.

\section{INTRODUCTION}

For individuals with end-stage symptomatic osteoarthritis of the knee, total knee
Strengths and limitations of this study

- Routinely collected data provided real-world evidence of costs and health outcomes following unicompartmental knee replacement (UKR) and total knee replacement (TKR).

- Propensity score matching was used to identify comparable individuals who received UKR or TKR.

- Differences between comparator groups may have remained in unobserved characteristics, such as preoperative radiographs

- Assumptions were required to extrapolate quality of life and risk of revision over patient lifetimes.

replacement (TKR) relieves pain and improves function. ${ }^{1}$ A substantial proportion of patients, by some estimates up to $50 \%,{ }^{2}$ could receive a unicompartmental knee replacement (UKR) instead. UKR is less invasive than TKR, sparing the normal joint surfaces and cruciate ligaments ${ }^{34}$ and consequently is associated with a faster recovery and lower risk of postoperative complications and mortality. ${ }^{56}$ In early and late comparisons of patient-reported outcome measures (PROMs), UKR has also been shown to result in superior outcomes, with a higher proportion of patients reporting an excellent result. ${ }^{78}$ However, UKR is also associated with a higher risk of revision than $\mathrm{TKR}^{5}{ }^{5}$ with this due in large part to a lower threshold for revision. ${ }^{9}$

The choice between UKR and TKR also has economic implications. Given that typical length of stay is lower for UKR, ${ }^{5}$ undertaking a UKR can be expected to require fewer healthcare system resources than a TKR. This upfront cost-saving could, however, be offset by the cost of additional reoperations and revisions. Differences in outcomes, in terms 
of pain and function, may also lead to differences in primary healthcare utilisation, which would further affect the overall costs of the procedures.

The relative merit of each procedure can be expected to vary depending on patient and surgical factors. Outcomes following UKR, in particular, are impacted by surgical factors. Surgeons' caseload (the number of UKR performed) and usage of UKR (the percentage of their primary knee replacements that are UKRs) have been shown to have a substantial impact on the success of UKR with those performed by high usage surgeons expected to have comparable reoperation rates with TKR. $^{10}$

Cost-effectiveness analyses offer a means of reducing decision uncertainty by providing a comparative analysis of both the costs and health outcomes of UKR and TKR. Our aim in this study was to estimate the cost-effectiveness of UKR compared with TKR based on routinely collected data from the UK and, in particular, to assess how cost-effectiveness varies depending on (1) the age and gender of patients and (2) surgeon usage of UKR.

\section{MATERIALS AND METHODS}

\section{Target population and subgroups}

The study population for this analysis is comprised of those patients who could receive either a UKR or TKR. We use propensity score matching to identify those patients who received a TKR who were similar to patients who received a UKR in all relevant observable characteristics and assume both groups to be eligible for a UKR but ultimately receiving either a TKR or a UKR. We consider the cost-effectiveness of UKR compared with TKR in terms of six subgroups based on age $(<60$ years, $60-75$ years and $>75$ years) and gender. In a further analysis, we consider the effect of surgeon 'usage' of UKR on cost-effectiveness for two subgroups $(<10 \%$ and $\geq 10 \%)$.

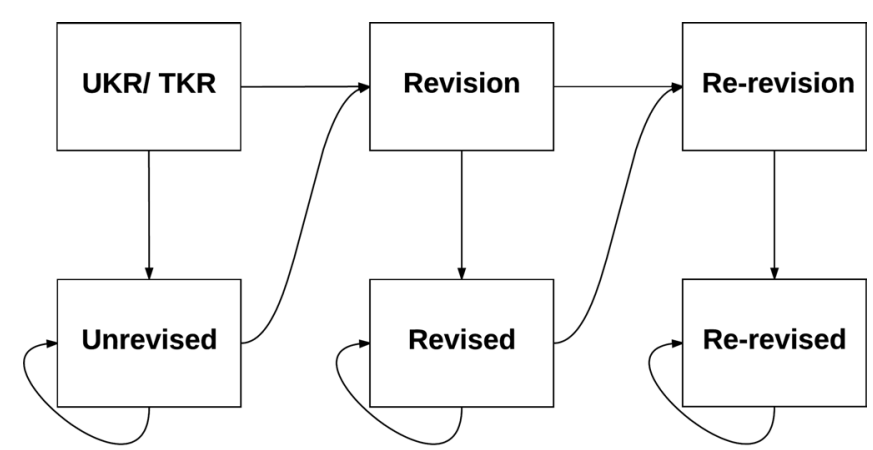
Death

Figure 1 Model outline. The decision analytic model provides the framework for the analysis. TKR, total knee replacement; UKR, unicompartmental knee replacement.

\section{Decision model}

A lifetime Markov model, shown in figure 1, provides the framework for the analysis, with patients passing through clinically and economically important health states as time passes. ${ }^{11}$ Patients begin by having a primary UKR or TKR, after which they have a revision operation or remain unrevised. After a revision, patients can have a further revision (re-revised) or remain revised. Following a re-revision, patients remain as re-revised until death. From all health states, patients have a risk of death, and the model goes through consecutive cycles until all patients have died. Patients can transition between states on a yearly basis. The key simplifying assumptions of the model are that patients can have only two revisions and that only one revision can occur in a year. While reoperations are not incorporated as a model state, their likelihood and costs are incorporated into the unrevised state.

\section{Study perspective}

This evaluation has been undertaken from a healthcare system perspective, hence only the costs incurred by the health system are included. These costs relate to surgical procedures being undertaken and primary care utilisation by patients. For healthcare interventions to be considered cost-effective (ie, providing sufficient value for money to merit their provision) in England, they should have an incremental cost per additional quality-adjusted life year (QALY) of less than $£ 20000-£ 30000 .{ }^{12}$ For this analysis, the cost-effectiveness of UKR is considered at the lower threshold of $£ 20000$.

\section{Measurement of effectiveness}

An extract of data from the National Joint Registry (NJR) for England and Wales linked to the Hospital Episode Statistics database and the Office for National Statistics informed estimates of the effectiveness of UKR and TKR. These data were previously used to compare adverse events following the procedures, with propensity scores used to match 25334 UKRs to 75996 comparable TKRs who received their primary procedure between 2003 and 2012. ${ }^{10}$ These same matched patients were split into the age and gender subgroups for this analysis. As surgeon usage of UKR was not a variable in the original propensity score matching, matching was rerun to achieve balance within usage subgroups (see online supplementary appendix). This ensured that the comparator groups, UKR performed by surgeons with usage under $10 \%$ against TKR, and UKR by surgeons with usage equal to or over $10 \%$ against TKR, were balanced in their observable characteristics.

Parametric models were specified independently for each treatment subgroup to estimate the risk of revision and death. For the base case analysis, the Weibull distribution was used for both. The risk of revision was extrapolated using estimates from the models, and risk of death was assumed to return to that given by age-specific and gender-specific UK life tables after the period of follow-up. ${ }^{13}$ Sensitivity analyses were performed for the 
risk of revision with the analysis rerun using the log-normal and exponential distributions instead of the Weibull. Further details of the estimated parametric models are provided in the online supplementary appendix.

Risk of re-revision was based on evidence from the NJR, which reported that in the first year following a revision, patients have a $2.7 \%$ probability of a re-revision and a $1.4 \%$ chance in subsequent years. ${ }^{14}$ With risk of re-revision being similar following a revision of UKR and TKR, ${ }^{15}$ these risks were applied in the same manner for both procedures. Risk of mortality following a revision and re-revision was assumed to be equal to that of those unrevised.

\section{Estimating resource use and costs}

The hospital costs associated with the primary procedures and revisions were based on patients' Healthcare Resource Group codes (which classify episodes with similar levels of resource consumption into the same group) and length of stay, with costs estimated using the 2014/2015 National Tariff Payment System. ${ }^{16}$ In addition, the costs of any implant-retaining reoperations over the five years following each surgery were also incorporated. We assumed the cost of a re-revision was the same as a revision in the base case analysis. The effect of this assumption on the results was tested by rerunning the analysis with a re-revision expected to have a cost 50\% higher than that of a revision.

For primary care costs an extract of the Clinical Practice Research Datalink was used where 335 UKRs were matched with 1005 TKRs based on propensity scores. These patients and their costs are summarised in the online supplementary appendix. The choice of procedure was found to have no significant effect on resource use and so the costs of treatment groups were pooled, and single estimates were extracted for each age and gender subgroup.

Future costs and health outcomes were discounted by an annual rate of 3.5\%, in line with guidelines for England and Wales. ${ }^{17}$ Costs are in British pounds, in 2014 prices. Estimated hospital and primary care costs are detailed in the online supplementary appendix.

\section{Measurement and valuation of preference-based outcomes}

As PROMs have only been collected for patients undergoing knee replacements in the English NHS since 2009, a separate propensity score matched cohort of 3519 UKRs and 10557 TKRs for whom these data were available were used to inform estimates of health-related quality of life for each subgroup considered. Again, these patients and the process of matching have been previously described in detail, ${ }^{7}$ and matching was rerun for usage subgroups (see online supplementary appendix). EuroQol-5D (EQ-5D) is a generic measure of health-related quality of life, whose preference-based scores for England range from -0.59 (worst) to 1 (best), with 0 representing death and 0.074 considered a minimally important difference. ${ }^{18}$
In the year following a primary, patients were expected to steadily progress from their preoperative score to their postoperative score at sixmonths, at which they would remain for the rest of that year. As EQ-5D following UKR and TKR has been shown to remain stable over 10 years following surgery for unrevised patients, ${ }^{8}$ in the absence of any further procedure, those unrevised were expected to remain at their postoperative score. The trajectory of quality of life following revision was assumed to be similar to primary procedures, with patients expected to progress from their preoperative score to their postoperative score over six months, at which point they were expected to remain unless they went on to have a re-revision. However, due to the small number of individuals with a revision and scores available, subgroups were pooled for revision parameters. We assumed quality of life for a re-revision would fall by the same proportion as it did from primary to a revision procedure. To test the impact of this assumption, we conducted a sensitivity analysis where the quality of life for a re-revision was assumed instead to remain equal to that of revision. Estimates of health-related quality-of-life were based on EQ-5D collected prior to and six months following surgery (see online supplementary appendix).

\section{Analytic methods}

Expected (mean) costs and QALYs were estimated for each subgroup receiving either UKR or TKR. The resulting incremental cost-effectiveness ratio (ICER) was then calculated (equal to the difference in costs divided by the difference in QALYs), with an intervention being considered dominant if it both reduced costs and increased QALYs. ${ }^{19}$ The effect of parameter uncertainty was assessed using probabilistic sensitivity analysis, with input parameters assigned from probability distributions and 1000 Monte Carlo simulations conducted for each subgroup. Probability distributions were based on the type of data, with gamma distributions used for costs as well as preoperative quality of life so as to allow values below zero, beta distributions used for postoperative quality of life and normal distributions used for the coefficients of parametric models and age. ${ }^{2021}$ The sets of estimated costs and QALYs from each of 1000 Monte Carlo simulations are presented, alongside the expected results, on a cost-effectiveness plane.

\section{Patient and public involvement}

No patients were involved in the development of the research question or the outcome measures nor the design of the study. There are no plans to disseminate the results of the research to study participants.

\section{RESULTS}

Compared with TKR, UKR was found to be associated with a greater likelihood of revision over individuals remaining lifetimes for each of the subgroups. UKR was, however, associated with better postoperative quality 


\begin{tabular}{|c|c|c|c|c|c|c|c|}
\hline & \multicolumn{2}{|l|}{ TKR } & \multicolumn{2}{|l|}{ UKR } & $\triangle$ QALYs & $\Delta$ Costs $(£)$ & $\begin{array}{l}\text { ICER } \\
\text { (probability } \\
\text { UKR cost- } \\
\text { effective*) }\end{array}$ \\
\hline $\begin{array}{l}\text { Male, } \\
<60 \\
\text { years }\end{array}$ & $\begin{array}{l}10.28 \\
(10.07 \text { to } 10.47)\end{array}$ & $\begin{array}{l}15357 \\
\text { (14704 to } 16019)\end{array}$ & $\begin{array}{l}10.39 \\
(10.11 \text { to } 10.70)\end{array}$ & $\begin{array}{l}14134 \\
\text { (13489 to } 14810)\end{array}$ & $\begin{array}{l}0.12 \\
(-0.19 \text { to } 0.47)\end{array}$ & $\begin{array}{l}-1223 \\
(-1439 \text { to }-1014)\end{array}$ & $\begin{array}{l}\text { UKR dominant } \\
(87 \%)\end{array}$ \\
\hline $\begin{array}{l}\text { Male, } \\
75+ \\
\text { years }\end{array}$ & $\begin{array}{l}5.61 \\
\text { (5.49 to } 5.73 \text { ) }\end{array}$ & $\begin{array}{l}11454 \\
\text { (10506 to } 12511)\end{array}$ & $\begin{array}{l}5.80 \\
\text { (5.64 to } 5.97)\end{array}$ & $\begin{array}{l}9450 \\
\text { (8442 to } 10631)\end{array}$ & $\begin{array}{l}0.19 \\
(0.02 \text { to } 0.37)\end{array}$ & $\begin{array}{l}-2005 \\
(-2361 \text { to }-1521)\end{array}$ & $\begin{array}{l}\text { UKR dominant } \\
(100 \%)\end{array}$ \\
\hline $\begin{array}{l}\text { Female, } \\
<60 \\
\text { years }\end{array}$ & $\begin{array}{l}10.68 \\
(10.50 \text { to } 10.89)\end{array}$ & $\begin{array}{l}16961 \\
\text { (16101 to } 17899)\end{array}$ & $\begin{array}{l}10.78 \\
(10.42 \text { to } 11.09)\end{array}$ & $\begin{array}{l}16360 \\
(15514 \text { to } 17273)\end{array}$ & $\begin{array}{l}0.10 \\
(-0.33 \text { to } 0.47)\end{array}$ & $\begin{array}{l}-601 \\
(-887 \text { to }-350)\end{array}$ & $\begin{array}{l}\text { UKR dominant } \\
(72 \%)\end{array}$ \\
\hline $\begin{array}{l}\text { Female, } \\
75+ \\
\text { years }\end{array}$ & $\begin{array}{l}6.02 \\
(5.82 \text { to } 6.15)\end{array}$ & $\begin{array}{l}11410 \\
\text { (10541 to } 12378)\end{array}$ & $\begin{array}{l}6.46 \\
(6.20 \text { to } 6.69)\end{array}$ & $\begin{array}{l}10308 \\
\text { (9312 to } 11378)\end{array}$ & $\begin{array}{l}0.44 \\
(0.18 \text { to } 0.71)\end{array}$ & $\begin{array}{l}-1102 \\
(-1646 \text { to }-695)\end{array}$ & $\begin{array}{l}\text { UKR dominant } \\
(100 \%)\end{array}$ \\
\hline
\end{tabular}

Expected (mean) values with $95 \%$ Cls in parentheses. UKR is considered 'dominant' if it is expected to improve health outcomes and reduce healthcare costs.

*Given a cost-effectiveness threshold of £20000.

ICER, incremental cost-effectiveness ratio; QALYs, quality-adjusted life years; TKR, total knee replacement; UKR, unicompartmental knee replacement.

of life following the primary procedure than TKR for all age and gender subgroups, with the difference most pronounced for older patients. Moreover, those undergoing revision following UKR had better quality of life prior to and following revision than those who had TKR. For all subgroups, the hospital costs of primary and revision surgery were lower for UKR than TKR. See online supplementary appendix for further details.

UKR was found to be cost-saving and health improving compared with TKR for all age and gender subgroups, making UKR the dominant treatment choice for those individuals eligible for either procedure (see table 1). The largest expected savings were for males over 75 years, while the biggest improvement in quality of life was for females over 75 years. For those aged over 60 years of age, parameter uncertainty had little effect on the conclusion that UKR was cost-effective. However, for those under 60 years, there was some uncertainty, with a $13 \%$ and $28 \%$ probability that TKR was cost-effective for males and females under 60 years, respectively.

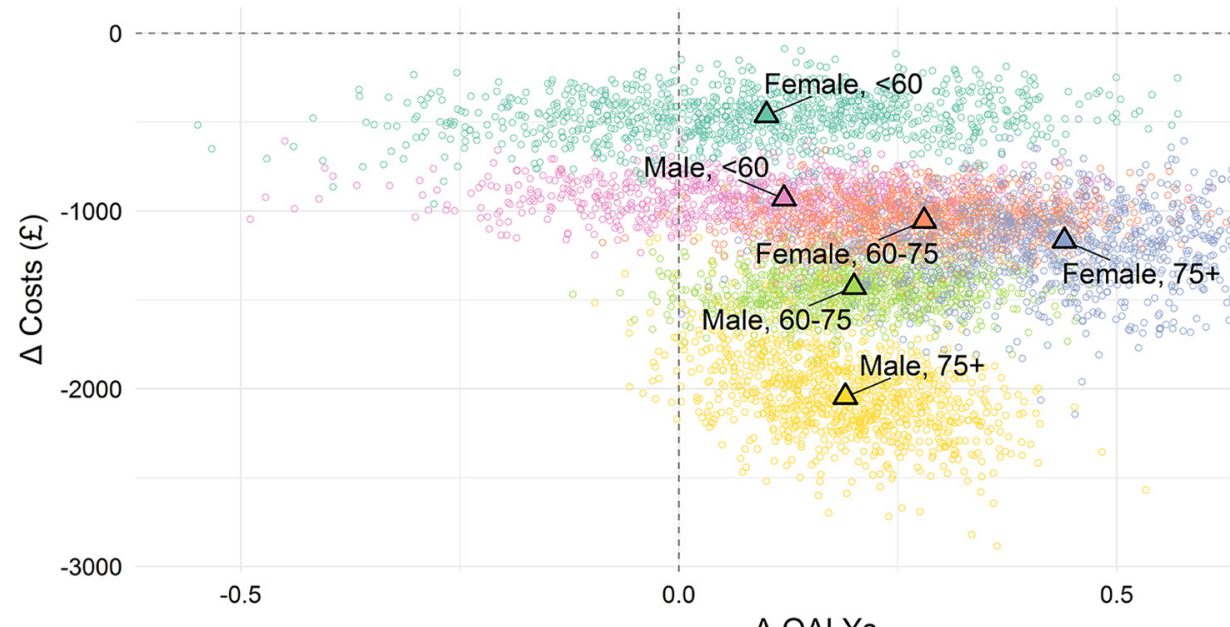

$\triangle$ QALYS

Figure 2 Cost-effectiveness plane for age and gender subgroups. The sets of estimated incremental costs and QALYs associated with the provision of UKR rather than TKR from each of the Monte Carlo simulations are shown as points with the expected results as triangles. QALYs, quality-adjusted life years; TKR, total knee replacement; UKR, unicompartmental knee replacement. 
Table 2 Scenario analyses

\begin{tabular}{|c|c|c|c|c|c|c|}
\hline & \multicolumn{2}{|c|}{ Age and gender subgroups } & \multirow[b]{2}{*}{ Male, $75+$ years } & \multirow[b]{2}{*}{$\begin{array}{l}\text { Female, }<60 \\
\text { years }\end{array}$} & \multirow[b]{2}{*}{$\begin{array}{l}\text { Female, 60-75 } \\
\text { years }\end{array}$} & \multirow[b]{2}{*}{$\begin{array}{l}\text { Female, } 75+ \\
\text { years }\end{array}$} \\
\hline & Male, $<60$ years & $\begin{array}{l}\text { Male, 60-75 } \\
\text { years }\end{array}$ & & & & \\
\hline \multicolumn{7}{|c|}{ Distribution of parametric model for revision risk } \\
\hline Log-normal & $\begin{array}{l}\text { UKR dominant } \\
(89 \%)\end{array}$ & $\begin{array}{l}\text { UKR dominant } \\
(100 \%)\end{array}$ & $\begin{array}{l}\text { UKR dominant } \\
(100 \%)\end{array}$ & $\begin{array}{l}\text { UKR dominant } \\
(77 \%)\end{array}$ & $\begin{array}{l}\text { UKR dominant } \\
(100 \%)\end{array}$ & $\begin{array}{l}\text { UKR dominant } \\
(100 \%)\end{array}$ \\
\hline \multicolumn{7}{|l|}{ Health utility } \\
\hline $\begin{array}{l}\text { Re-revision } \\
\text { equal to } \\
\text { revision }\end{array}$ & $\begin{array}{l}\text { UKR dominant } \\
(95 \%)\end{array}$ & $\begin{array}{l}\text { UKR dominant } \\
(100 \%)\end{array}$ & $\begin{array}{l}\text { UKR dominant } \\
(100 \%)\end{array}$ & $\begin{array}{l}\text { UKR dominant } \\
(91 \%)\end{array}$ & $\begin{array}{l}\text { UKR dominant } \\
(100 \%)\end{array}$ & $\begin{array}{l}\text { UKR dominant } \\
(100 \%)\end{array}$ \\
\hline \multicolumn{7}{|l|}{ Cost } \\
\hline $\begin{array}{l}\text { Cost of re- } \\
\text { revision } 50 \% \\
\text { higher than } \\
\text { revision }\end{array}$ & UKR dominant & UKR dominant & UKR dominant & UKR dominant & UKR dominant & UKR dominant \\
\hline
\end{tabular}

Incremental cost-effectiveness ratio (ICER) with probability of UKR being cost-effective, based on probabilistic sensitivity analysis and given a cost-effectiveness threshold of $£ 20000$, in parentheses. UKR is considered 'dominant' if it is expected to improve health outcomes and reduce healthcare costs. Full results for each scenario analysis are detailed in the online supplementary appendix.

UKR, unicompartmental knee replacement.

Figure 2 presents the estimated mean and probabilistic sets of incremental costs and QALYs associated with the provision of UKR rather than TKR for each age and gender subgroup. These findings were broadly robust to changes in modelling assumptions (see table 2 and online supplementary appendix for full results from each scenario analysis).

When UKR was performed by surgeons with a usage of the procedure equal to or above 10\% (median usage was 27\%), UKR was found to be unequivocally cost-saving and health improving compared with TKR, as shown in table 3 . When performed by surgeons with usage of less than $10 \%$ (median usage was 6\%), however, UKR was no longer expected to lead to better health outcomes than TKR, and TKR became the more likely cost-effective procedure. Figure 3 presents the estimated means and sets of costs and QALYs for both usage subgroups.

\section{DISCUSSION}

\section{Principal findings}

For patients who are eligible for either procedure, the provision of UKR rather than TKR has been estimated to lead to a gain in QALYs and a reduction in costs for all age and gender subgroups. There is little uncertainty around this conclusion for older patients. Such patients have, given their lower life expectancy, a lower lifetime risk of revision and report greater improvements in postoperative quality of life compared with TKR than younger

\begin{tabular}{|c|c|c|c|c|c|c|c|}
\hline & \multicolumn{2}{|l|}{ TKR } & \multicolumn{2}{|l|}{ UKR } & \multirow[b]{2}{*}{$\triangle$ QALYs } & \multirow[b]{2}{*}{$\Delta$ Costs $(£)$} & \multirow{2}{*}{$\begin{array}{l}\text { ICER } \\
\text { (probability UKF } \\
\text { cost-effective }{ }^{\star} \text { ) }\end{array}$} \\
\hline & QALYS & Costs (£) & QALYS & Costs (£) & & & \\
\hline UKR $<10 \%$ & $\begin{array}{l}8.67 \\
\text { (8.53 to } 8.80)\end{array}$ & $\begin{array}{l}13267 \\
\text { (12834 to } 13731)\end{array}$ & $\begin{array}{l}8.62 \\
\text { ( } 8.38 \text { to } 8.84 \text { ) }\end{array}$ & $\begin{array}{l}13140 \\
(12643 \text { to } 13614)\end{array}$ & $\begin{array}{l}-0.04 \\
(-0.32 \text { to } 0.21)\end{array}$ & $\begin{array}{l}-127 \\
(-429 \text { to } 127)\end{array}$ & $\begin{array}{l}£ 3000 / Q A L Y \\
(37 \%)\end{array}$ \\
\hline$U K R \geq 10 \%$ & $\begin{array}{l}8.81 \\
\text { (8.73 to } 8.88)\end{array}$ & $\begin{array}{l}13170 \\
(12726 \text { to } 13614)\end{array}$ & $\begin{array}{l}9.06 \\
\text { (8.94 to } 9.18)\end{array}$ & $\begin{array}{l}12411 \\
\text { (11978 to } 12856)\end{array}$ & $\begin{array}{l}0.26 \\
(0.12 \text { to } 0.40)\end{array}$ & $\begin{array}{l}-758 \\
(-939 \text { to }-579)\end{array}$ & $\begin{array}{l}\text { UKR dominant } \\
(100 \%)\end{array}$ \\
\hline
\end{tabular}

Expected (mean) values with $95 \%$ Cls in parentheses. UKR is considered 'dominant' if it is expected to improve health outcomes and reduce healthcare costs.

*Given a cost-effectiveness threshold of $£ 20000$.

ICER, incremental cost-effectiveness ratio; QALYs, quality-adjusted life years; TKR, total knee replacement; UKR, unicompartmental knee replacement. 


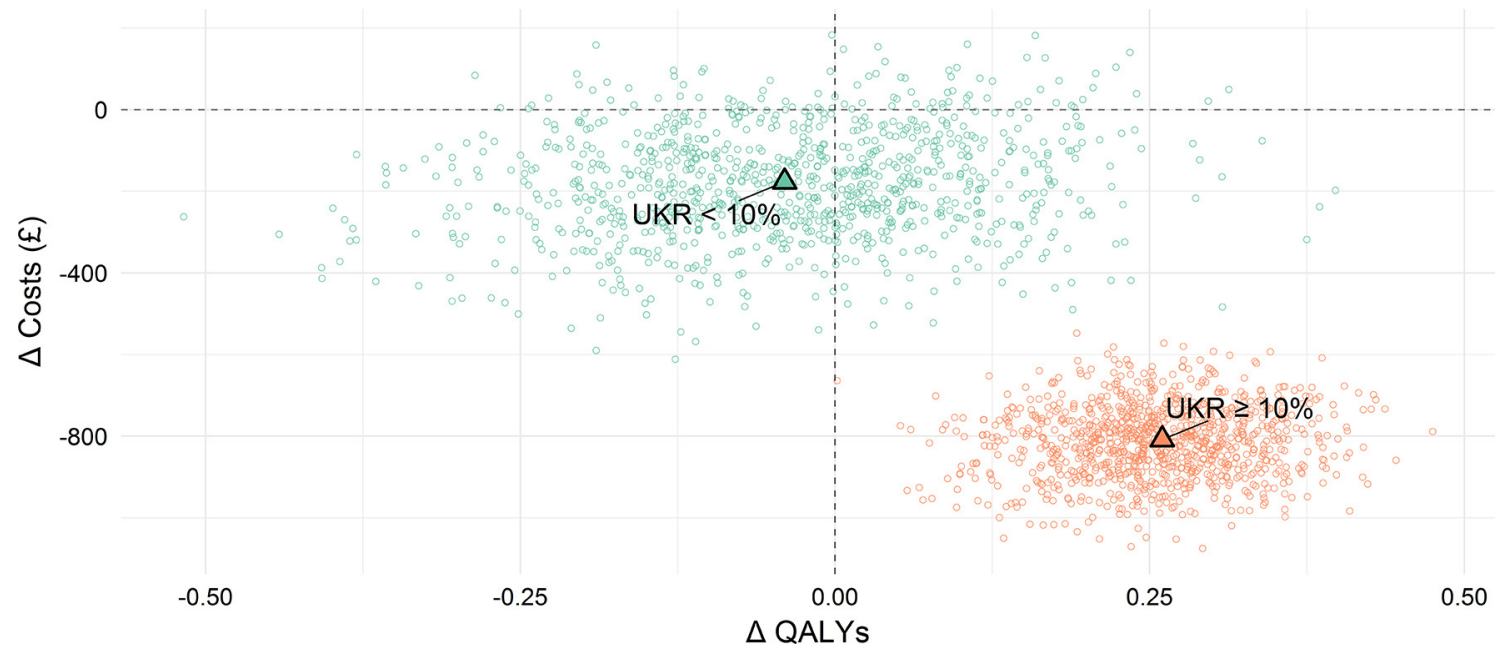

Figure 3 Cost-effectiveness plane for usage subgroups. The sets of estimated incremental costs and QALYs associated with the provision of UKR rather than TKR from each of the Monte Carlo simulations are shown as points with the expected results as triangles. QALYs, quality-adjusted life year; TKR, total knee replacement; UKR, unicompartmental knee replacement.

patients. Significant uncertainty does surround whether UKR would be health improving for younger patients for whom even relatively small differences in annual revision rates lead to substantial differences in lifetime revision rates.

Surgeon usage of UKR, that is, the percentage of the knee replacements they perform that were UKRs, had a significant impact on the cost-effectiveness of the procedure. UKR was expected to be cost-effective when compared with TKR with $100 \%$ probability (given parameter uncertainty) when performed by surgeons with usage at or above $10 \%$, with these surgeons having a median usage of $27 \%$. However, when UKR performed by low usage surgeons were compared against TKR, TKR was the more likely cost-effective option.

\section{Limitations of the study}

Our analysis was based on routinely collected data from the National Health Service in England and Wales. While this dataset has the advantage of providing real-world evidence for costs and health outcomes following UKR and TKR, it also has the potential pitfalls of any such observational data. In particular, confounding by indication can be expected with treatment selection based on patient and surgical characteristics. Propensity score matching was used to achieve balance in a wide range of observed characteristics; however, imbalances may still exist in unobserved factors that could bias the findings of the study. In particular, it was not possible to include preoperative radiographs, which would provide a better assessment of patients eligible to have either procedure; hence, differences in these may have persisted between matched groups.

With costs and health outcomes estimated over the remaining lifetimes of patients, modelling assumptions were unavoidable. Individuals' risk of revision over their remaining lifetimes were based on observed revisions over the eightyears following surgery. In addition, quality of life estimates were based on scores recorded prior to and sixmonths following primary and revision procedures, and we assumed that, in the absence of further procedures, individuals would remain at their postoperative scores into the future. This assumption appears to be plausible following primary procedures ${ }^{8}$; however, it is uncertain whether a similar pattern would be seen following revisions. If quality of life following revision steadily returned to comparable levels observed after primary procedures, the cost-effectiveness of UKR, which has a higher risk of revision, will have been somewhat underestimated. Furthermore, we assumed quality of life associated with re-revision would have dropped by the same proportion as that observed from primary to revision and the cost of a re-revision was assumed to be equivalent to that of a revision. These assumptions were necessarily subjective; however, scenario analyses showed the findings of the study to be robust to changes in these assumptions.

\section{Study findings in context}

In line with findings from previous economic evaluations of UKR and TKR, ${ }^{22}$ in this study, we found UKR to be less costly than TKR. Furthermore, consistent with previous research, UKR was also found to lead to better health outcomes for patients aged 65 years and over. Little uncertainty surrounds this conclusion for older patients, who benefit most from a less invasive procedure and have a low lifetime risk of revision. For younger patients, whose health outcomes are mixed, ${ }^{23-25}$ this analysis found that UKR was also expected to lead to better health outcomes than TKR, although there was significant uncertainty in this conclusion. The variation in findings for younger patients across studies appears to be driven by differences in estimates for both the risk of revision and the expected effect of revision on quality of life.

This study has also highlighted the importance of surgeon usage of UKR on the cost-effectiveness of the 
procedure. In the high usage group, with a median usage of $27 \%$, UKR was found, with no parameter uncertainly, to lead to better health outcomes and to cost-savings compared with TKR. In contrast, in the low usage group, UKR led to expected worse health outcomes and only small cost savings. High-usage surgeons appear to achieve good results following UKR regardless of their caseload of the procedure, and so the poor results of those with low usage appear to be primarily due to inappropriate patient selection. ${ }^{26}$ In particular, low-usage surgeons seem more likely to offer UKR to patients with partial-thickness cartilage loss (PTCL). PTCL is associated with poor outcomes following UKR and so it has been recommended that UKR should only be undertaken for individuals with bone-on-bone arthritis. ${ }^{10}$ High-usage surgeons, therefore, should be supported, while low-usage surgeons should consider changing their practice. If surgeons with low or no usage of UKR learnt and applied the indications and techniques of current high-usage surgeons, they can be expected to achieve similar results.

\section{CONCLUSIONS}

For those patients with appropriate indications, UKR provides an alternative to TKR that is less costly for the healthcare system to provide and leads to better health outcomes over their lifetime. If surgeons performing UKR achieved sufficient usage of the procedure, future economic and population health gains would likely be increased even further. Additional work is needed to identify the optimal usage of UKR, which may depend on the type of implants used. Surgeons should not have a low usage and be performing UKR in less than $10 \%$ of their knee replacements. The median usage in the high usage group was $27 \%$, so it would be reasonable for surgeons to aim for a quarter of their knee replacements to be UKR. However, it has been shown that up to $50 \%$ of replacements could be UKR, so the optimal usage may be higher.

\section{Author affiliations}

${ }^{1}$ Nuffield Department of Orthopaedics, Rheumatology and Musculoskeletal Sciences, University of Oxford, Oxford, UK

${ }^{2}$ Institute of Orthopaedics and Musculoskeletal Sciences, Royal National Orthopaedic Hospital, University College London, Stanmore, UK

${ }^{3}$ MRC Lifecourse Epidemiology Unit, University of Southampton, Southampton General Hospital, Southampton, UK

${ }^{4}$ Musculoskeletal Research Unit, Translational Health Sciences, Bristol Medical School, University of Bristol, Bristol, UK

${ }^{5}$ Nuffield Orthopaedic Centre, Oxford University Hospitals NHS Foundation Trust, Oxford, UK

Acknowledgements We would like to thank the patients and staff of all the hospitals in England and Wales who have contributed data to the National Joint Registry (NJR); and the Healthcare Quality Improvement Partnership (HQIP), the NJR Steering Committee and staff at the NJR Centre for facilitating this work. The authors have conformed to the NJR's standard protocol for data access and publication.

Contributors All authors made substantial contributions to conception and design of the study. EB, ADL and RP-V undertook the statistical analysis. EB, DWM and RP-V drafted the manuscript with ADL, TWH, AJ and HGP revising it for important intellectual content. All authors read and approved the final manuscript.
Funding This research was supported by funding from Zimmer Biomet. Zimmer Biomet had no other role in the design or conduct of the study. The research was supported by the National Institute for Health Research (NIHR) Oxford Biomedical Research Centre (BRC).

Disclaimer The views expressed represent those of the authors and do not necessarily reflect those of the NHS, the NIHR, the Department of Health, the National Joint Registry Steering Committee or the Healthcare Quality Improvement Partnership (HQIP) who do not vouch for how the information is presented. HES data copyright (C) 2013, re-used with the permission of the Health \& Social Care Information Centre. All rights reserved.

Competing interests All authors declare: financial support for the submitted work from Zimmer Biomet; HGP and DWM have received consultancy fees and DWM has received royalties from Zimmer Biomet; TWH and DWM hold various patents related to total and unicompartmental knee replacement.

Patient consent Not required.

Ethics approval Permission to access data was given by the National Information Governance Board, now the Confidentiality Advisory Group (application number ECC 1-02 (FT3)/2013).

Provenance and peer review Not commissioned; externally peer reviewed.

Data sharing statement Access to data is available from the National Joint Registry for England and Wales.

Open Access This is an Open Access article distributed in accordance with the Creative Commons Attribution Non Commercial (CC BY-NC 4.0) license, which permits others to distribute, remix, adapt, build upon this work non-commercially, and license their derivative works on different terms, provided the original work is properly cited and the use is non-commercial. See: http://creativecommons.org/ licenses/by-nc/4.0/

C) Article author(s) (or their employer(s) unless otherwise stated in the text of the article) 2018. All rights reserved. No commercial use is permitted unless otherwise expressly granted.

\section{REFERENCES}

1. Carr AJ, Robertsson O, Graves S, et al. Knee replacement. The Lancet 2012;379:1331-40.

2. Willis-Owen $\mathrm{CA}$, Brust $\mathrm{K}$, Alsop $\mathrm{H}$, et al. Unicondylar knee arthroplasty in the UK National Health Service: an analysis of candidacy, outcome and cost efficacy. Knee 2009;16:473-8.

3. Ashraf ST, Ackroyd CE, Newman JH. Compartmental knee arthroplasty. Curr Orthop 2003;17:134-43.

4. Lützner J, Kasten P, Günther KP, et al. Surgical options for patients with osteoarthritis of the knee. Nat Rev Rheumatol 2009;5:309-16.

5. Liddle AD, Judge A, Pandit $\mathrm{H}$, et al. Adverse outcomes after total and unicompartmental knee replacement in 101,330 matched patients: a study of data from the National Joint Registry for England and Wales. Lancet 2014;384:1437-45.

6. Hunt LP, Ben-Shlomo Y, Clark EM, et al. 45-day mortality after 467,779 knee replacements for osteoarthritis from the National Joint Registry for England and Wales: an observational study. Lancet 2014;384:1429-36.

7. Liddle AD, Pandit $H$, Judge A, et al. Patient-reported outcomes after total and unicompartmental knee arthroplasty: a study of 14,076 matched patients from the National Joint Registry for England and Wales. Bone Joint J 2015;97-B:793-801.

8. Burn E, Sanchez-Santos MT, Pandit HG, et al. Ten-year patientreported outcomes following total and minimally invasive unicompartmental knee arthroplasty: a propensity score-matched cohort analysis. Knee Surg Sports Traumatol Arthrosc 2016.

9. Goodfellow JW, O'Connor JJ, Murray DW. A critique of revision rate as an outcome measure: re-interpretation of knee joint registry data. $J$ Bone Joint Surg Br 2010;92:1628-31.

10. Liddle $A D$, Pandit $H$, Judge $A$, et al. Optimal usage of unicompartmental knee arthroplasty: a study of 41,986 cases from the National Joint Registry for England and Wales. Bone Joint $J$ 2015;97-B:1506-11.

11. Briggs $A$, Sculpher M. An introduction to Markov modelling for economic evaluation. Pharmacoeconomics 1998;13:397-409.

12. McCabe C, Claxton K, Culyer AJ. The NICE cost-effectiveness threshold: what it is and what that means. Pharmacoeconomics 2008;26:733-44.

13. ONS. National life tables: United Kingdom. 2016. https://www.ons. gov.uk/ 
14. National Joint Registry for England W. Northern Ireland and the Isle of Man. 13th annual report, 2016.

15. Leta TH, Lygre SH, Skredderstuen A, et al. Outcomes of unicompartmental knee arthroplasty after aseptic revision to total knee arthroplasty: a comparative study of 768 TKAs and 578 UKAs Revised to TKAs from the Norwegian Arthroplasty Register (1994 to 2011). J Bone Joint Surg Am 2016;98:431-40.

16. Monitor and NHS England. National tariff payment system 2014/15. 2013. https://www.gov.uk/government/publications/national-tariffpayment-system-2014-to-2015

17. NICE. Guide to the methods of technology appraisal 2013, 2013.

18. Walters SJ, Brazier JE. Comparison of the minimally important difference for two health state utility measures: EQ-5D and SF-6D. Qual Life Res 2005;14:1523-32.

19. Drummond M, McGuire A. Economic evaluation in health care: merging theory with practice. New York: Oxford University Press, 2001.

20. Briggs A, Sculpher M, Claxton K. Decision modelling for health economic evaluation: Oxford University Press, 2006.

21. Edlin R, McCabe C, Hulme C, et al. Cost effectiveness modelling for health technology assessment. A practical course: Adis, 2015.
22. Burn E, Liddle AD, Hamilton TW, et al. Choosing Between unicompartmental and total knee replacement: what can economic evaluations tell us? A systematic review. Pharmacoecon Open 2017;1:241-53.

23. Peersman G, Jak W, Vandenlangenbergh $\mathrm{T}$, et al. Cost-effectiveness of unicondylar versus total knee arthroplasty: a Markov model analysis. Knee 2014;21(Suppl 1):S37-S42.

24. Konopka JF, Gomoll AH, Thornhill TS, et al. The cost-effectiveness of surgical treatment of medial unicompartmental knee osteoarthritis in younger patients: a computer model-based evaluation. J Bone Joint Surg Am 2015;97:807-17.

25. Ghomrawi HM, Eggman AA, Pearle AD. Effect of age on costeffectiveness of unicompartmental knee arthroplasty compared with total knee arthroplasty in the U.S. J Bone Joint Surg Am 2015;97:396-402.

26. Hamilton TW, Rizkalla JM, Kontochristos $L$, et al. The interaction of caseload and usage in determining outcomes of unicompartmental knee arthroplasty: a meta-analysis. $J$ Arthroplasty 2017;32:3228-37. 